\title{
Production of Biodiesel Fuel from Waste Soya bean Cooking Oil by Alkali Trans-esterification Process
}

\section{AJINKYA DIPAK DESHPANDE*, PRATIKSINH DILIPSINH CHAVDA and HINA KADEVAL}

\author{
College of Renewable Energy and Environmental Engineering, Sardarkrushinagar Dantiwada \\ Agricultural University, Sk Nagar-385506, Gujarat, India.
}

http://dx.doi.org/10.12944/CWE.11.1.32

(Received: March 23, 2016; Accepted: April 13, 2016)

\begin{abstract}
Biodiesel is biodegradable, clean-burning, non-toxic, renewable, high-quality, and cheap diesel fuel made primarily from waste vegetable oil which can be used without any alterations in engine design. The paper is concerned with the extraction and quality evaluation of the biodiesel fuels synthesized from waste soya bean cooking oil. Waste soya bean cooking oil had high amount of free fatty acid. Thus, single step transesterification process with the aid of homogeneous catalyst as $1 \%$ potassium hydroxide were implemented in this experiment. Methanol was chosen as alcohol solvent. In the transesterification process, the triglycerides in waste cooking oil was reacted with a methanol to form esters and glycerol as byproduct. The biodiesel were extracted for different oil to methanol ratio as 1:2, 1:3 and 1:4. The highest biodiesel yield of $76 \%$ was obtained at 1:3 volumetric ratio for $60^{\circ} \mathrm{C}$ reaction temperature and $1250 \mathrm{rpm}$ stirring speed. Results show that the optimal methyl ester yield of $90 \%$ occurred at methanol: oil volume ratio of $3: 1$. The product met the ASTM fuel standards for relative density, acid value, relative density, calorific value, flash point and kinematic viscosity.
\end{abstract}

Keywords: Biodiesel; waste cooking oil; Waste cooking oil; alkali transesterification.

\section{INTRODUCTION}

Biofuels are the energy carriers that store the energy derived from biomass, commonly produced from plants, animals and micro-organisms and organic wastes. Biofuels may be solid, liquid or gaseous and include all kinds of biomass as well as derived products used for energy purposes. Biodiesel is one of the alternatives fuel used to run the vehicle. Biodiesel was introduced to the world by Rudolph Diesel, a Germany Engineer in 1895 which transform peanut oil into biodiesel ${ }^{1}$ but, at that time the petroleum diesel based fuel still abundant thus make biodiesel fact hidden. After a few years later in 1970s, the world petroleum reserves depleted ${ }^{2}$ and the earth start fighting with the environmental problems. This make biodiesel was taken into consideration as one of the efficient alternatives fuel.
Biodiesel was chosen as the alternative because its properties differ a bit from conventional diesel depended on the oil feedstock and alcohol used but very close to diesel fuel ${ }^{3}$. Waste oil is defined a synthetic oil that, has become unsuitable for cooking purpose due to the presence of high amount of impurities as well as loss of original properties. Waste Cooking Oil (WCO) generates from many sources, including domestic, commercial and industrial Food factories facing an environment problem of WCO. The production of biodiesel from waste cooking oil is one of the better ways to utilize it efficiently and economically. The price of WCO is 2-3 times cheaper than virgin vegetable oils. The soybean Production in India is approximately 13.34 million tons in 2013 \& 2014. In 2014, 1.61 million tons of soya bean oil and 1.39 million tons of cottonseed oil were produced in India. It was reported that the transesterification of 
pre-treated waste cooking oil maximum conversion at 6.5:1 of methanol to oil ratio 4 . With further increase in molar ratio the conversion efficiency more or less remains the same but the energy required for the recovery of methanol becomes higher. It was concluded that the use of waste cooking oils is an effective way to reduce the cost of biodiesel production ${ }^{5}$. The advantages of using waste cooking oils to produce biodiesel are the low cost and prevention of environment pollution. These oils need to be treating before dispose to the environment to prevent pollution. Due to the high cost of disposal, many individuals dispose waste cooking oils directly to the environment especially in rural area.

Recycled waste cooking oil is harmful to health, but it is not environmental friendly to dispose used cooking oil just like that. The best solution is to used it for industrial purposes, namely to reproduce into biodiesel. ${ }^{6}$ The highest biodiesel yield was obtained $(71.2 \%)$ under the conditions of $1: 1$ volumetric oil-to-methanol weight ratio, $0.5 \%$ $\mathrm{NaOH}$ catalyst at $50^{\circ} \mathrm{C}$ reaction temperature and 320 rpm stirring speed. The results showed that biodiesel produced from different oil to methanol ratios, alcohol types and shaking time exhibited considerable

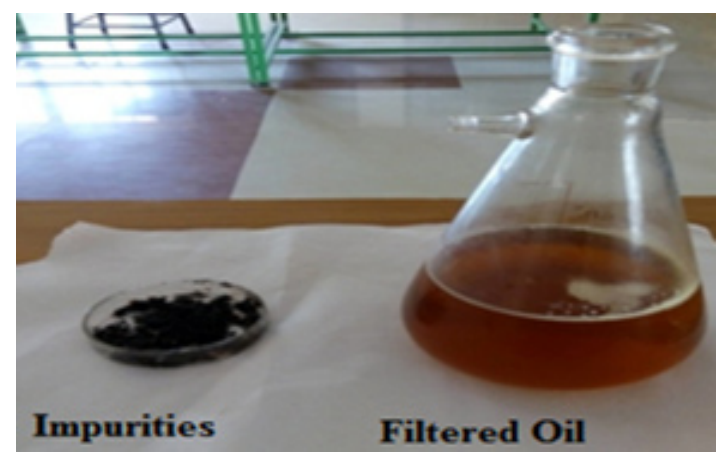

Fig. 1: Impurities \& Filtered Soya bean waste cooking Oil

Table 1: Characteristics of Fresh and Waste Soya Bean Oil differences. There was also a considerable difference of biodiesel yield produced by using methanol, ethanol and 1 butanol ${ }^{7}$.

\section{MATERIALS AND METHOD}

\section{Preparation of samples}

The raw soya bean waste cooking oil was procured from Sarojini home science girl's hostel. The contamination in the oil was filtered through $5 \mu$ filter cloth in vacuum filtration unit. The six samples of $1000 \mathrm{ml}$ each were filtered on this machine. The Fig. 1 displays filtered oil along with impurity found in collected soya bean waste cooking oil.

Three random samples were drawn from filtered soya bean waste cooking and evaluated for its Free Fatty Acid (FFA) content, Relative density, acid value, saponification number and ester value as illustrated in Table 1.

\section{Trans-Esterification Process}

One liter of waste soya bean cooking oil was taken in a flask and heated till temperature

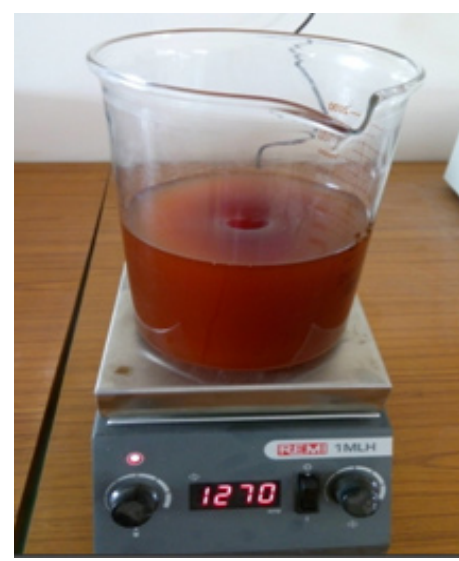

Fig. 2: Beaker on Magnetic Stirrer

\begin{tabular}{lcc}
\hline Property & Fresh Soya Bean Oil & Waste Soya Bean Oil \\
\hline FFA content $(\%)$ & 0.03 & 0.35 \\
Relative density $\left(\mathrm{kg} / \mathrm{m}^{3}\right)$ & 890 & 895 \\
Acid Value $(\mathrm{mg} \mathrm{KOH} / \mathrm{g}$ oil) & 0.3 & 0.56 \\
Saponification Number (mg KOH/g oil) & 193 & 175 \\
Ester Value (mg KOH/g oil) & 192.72 & 174.44 \\
\hline
\end{tabular}


reaches close to boiling point of methanol $\left(65-70^{\circ} \mathrm{C}\right)$ on magnetic stirrer at $1250 \mathrm{rpm}$ as shown in Fig. 2. The filtered waste cooking oil and methyl alcohol was used in 1:2, 1:3 and 1:4 proportions for extraction biodiesel. Potassium methoxide (a mixture of $\mathrm{KOH}$ and methanol) was added slowly to the beaker and heated for one and half hour at $70^{\circ} \mathrm{C}$ temperature. At the end of reaction, the sample was transferred to a separating funnel for glycerol separation as show in Fig. 3. In separation process, glycerol was settled down in bottom of separating funnel leaving biodiesel in upper portion.

\section{Washing of Product}

The produced biodiesel had traces of $\mathrm{KOH}$, methanol and glycerol. Thus, it was washed for 4 to 6 times by spraying hot distilled water of $40-50^{\circ} \mathrm{C}$

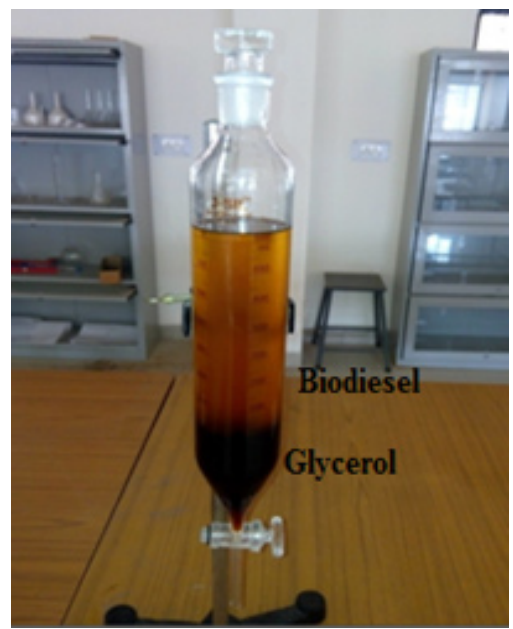

Fig. 3: Biodiesel-Glycerol separation

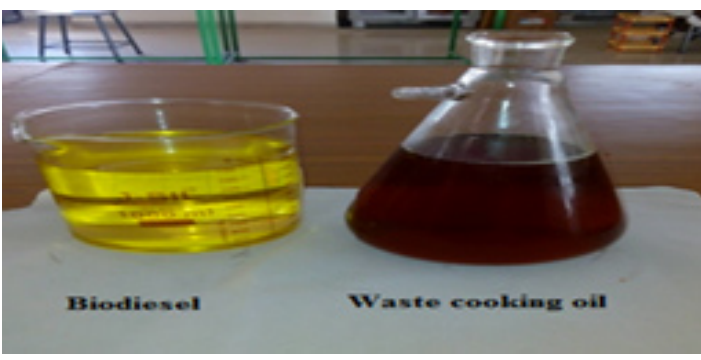

Fig. 5: Biodiesel and Waste Soybean cooking oil on the biodiesel and kept for separation. While separation process, the water was settled in bottom of separating funnel as shown in Fig. 4

\section{Heating of Product}

The washed biodiesel samples were heated to $110^{\circ} \mathrm{C}$ to remove the trapped traces of water in it. The final synthesized product was shown in Fig. 5 , 6 and 7.

\section{Production of biodiesel}

The lowest biogas yield of $73 \%$ was achieved in sample 3 having 1:4 waste cooking oil to methanol ratio as shown in Fig. 8. An optimal biodiesel yield of $76 \%$ was obtained for waste soya bean oil at 1:3 volumetric ratio of cooking oil and methanol.

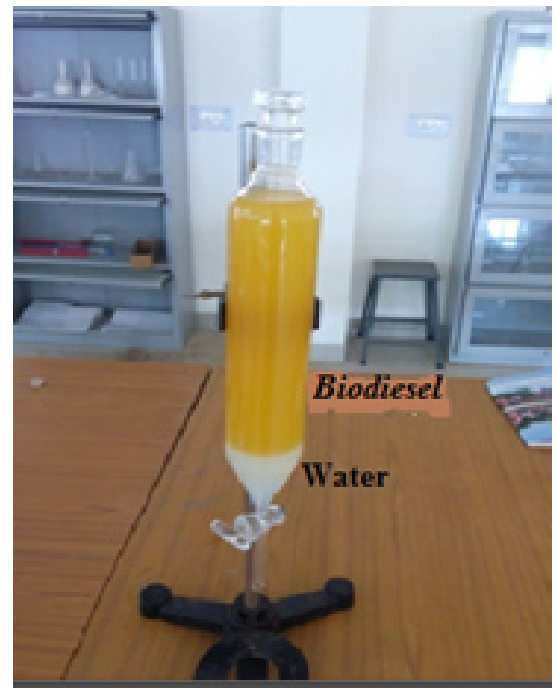

Fig. 4: Biodiesel washing

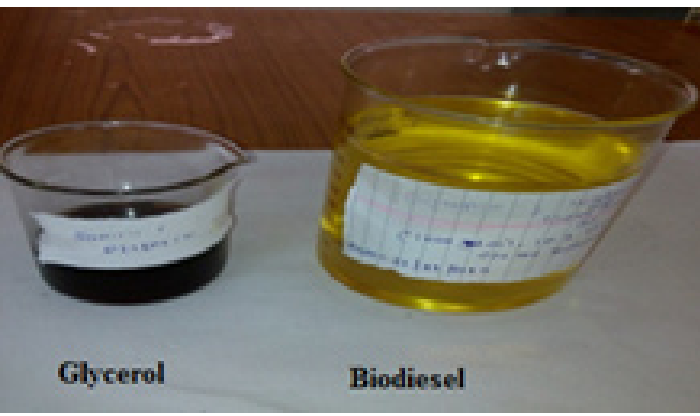

Fig. 6: Glycerol and Biodiesel 
Characteristic of waste cooking oil biodiesel

The characteristics of waste soya bean biodiesel were evaluated with relative density, acid value, higher calorific value, kinematic viscosity and flash point.

The previous research work showed that increasing methanol to oil molar ratio increased the yield of biodiesel production. Oil to methanol molar ratio of $1: 1$ gave the optimum yield of biodiesel among them. The yield of biodiesel was $71.2 \%$ for $1: 1$ of oil to methanol molar ratio ${ }^{7}$ but present study conclude that the 1:3 ratio of waste soybean oil to methanol will yield more biodiesel that other combinartions.

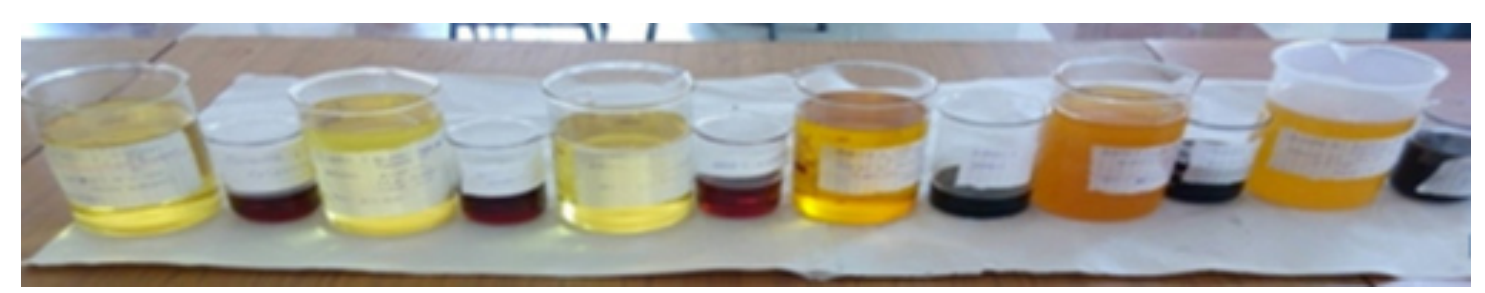

Fig. 7: Extracted Samples of Waste Soya Bean Oil Biodiesel with Glycerol

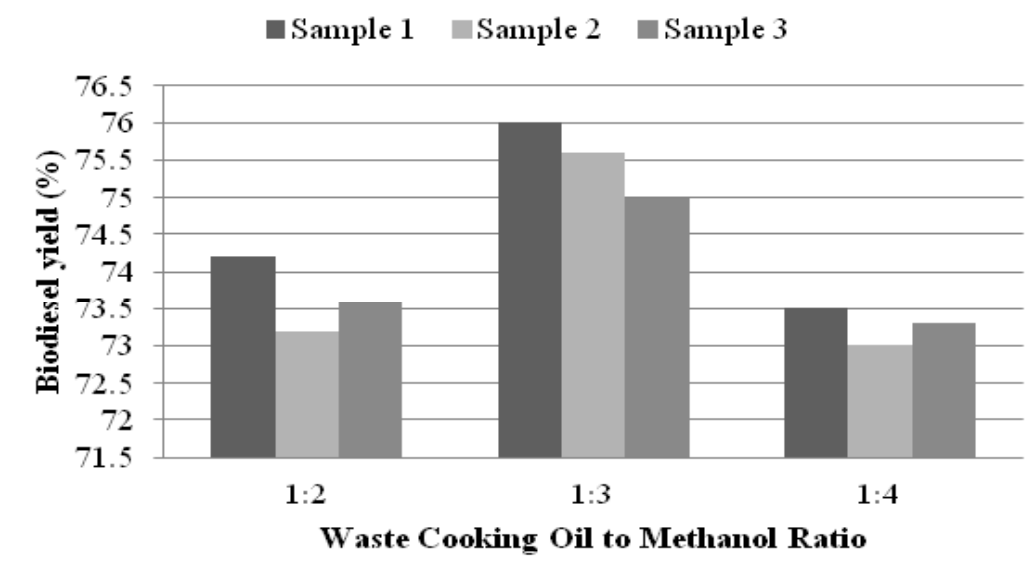

Fig. 8: Biodiesel yield at different waste soya bean cooking oil to methanol ratio

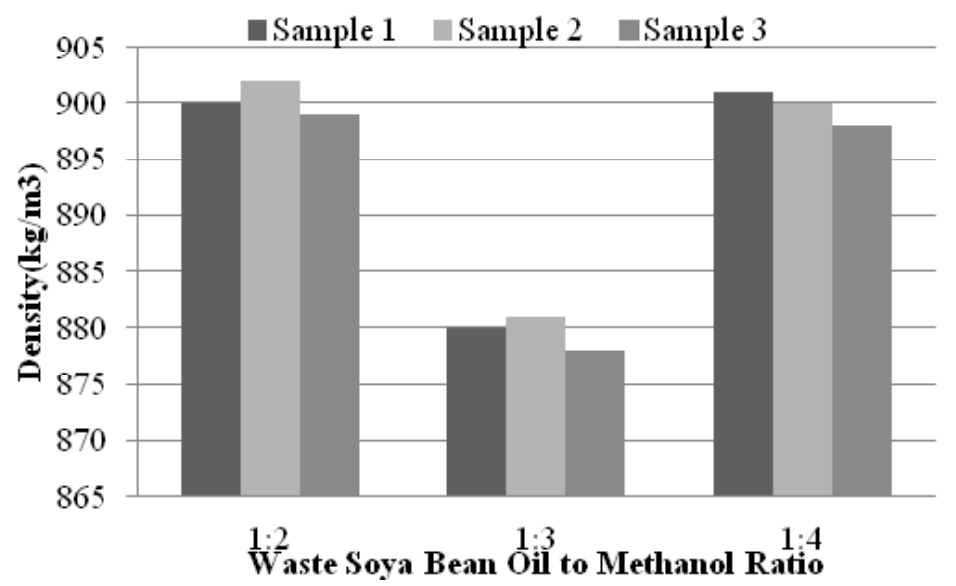

Fig. 9: Relative density of biodiesel samples produced at different oil to methanol ratio 


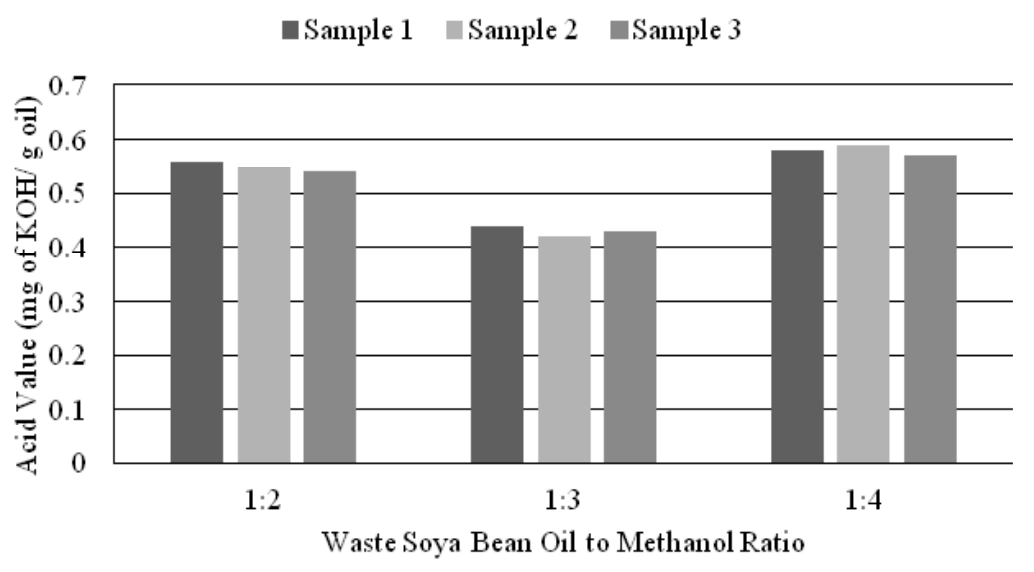

Fig. 10: Acid value of biodiesel produced at different oil to methanol ratio

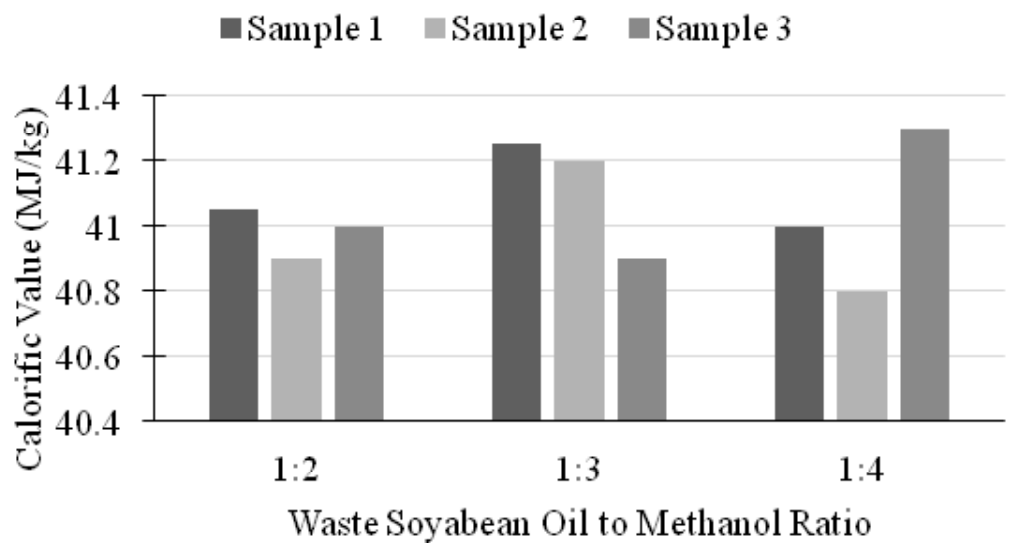

Fig. 11: Calorific value of biodiesel produced at different oil to methanol ratio

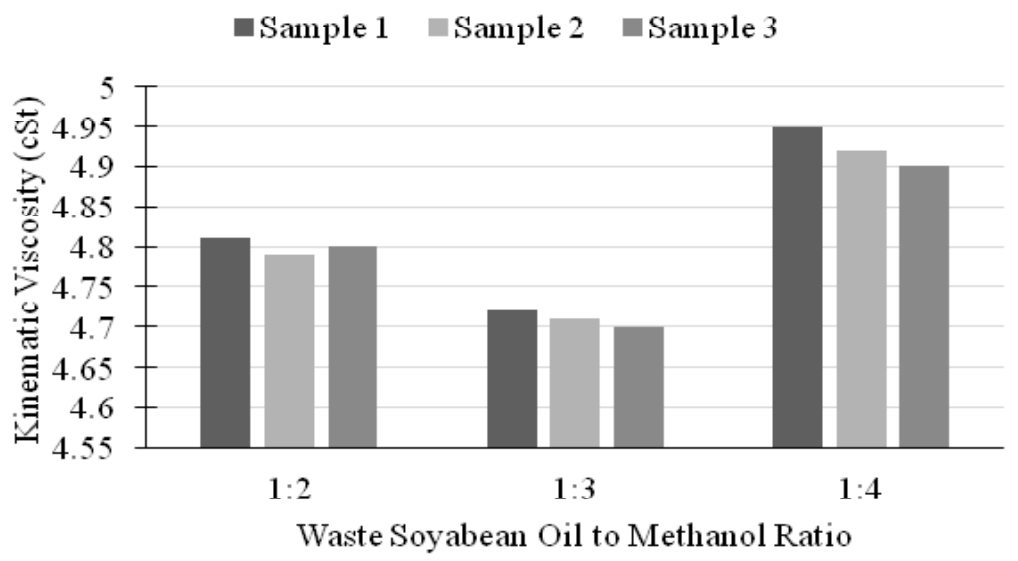

Fig. 12: Kinematic Viscosity of Biodiesel produced at different oil to methanol ratio 


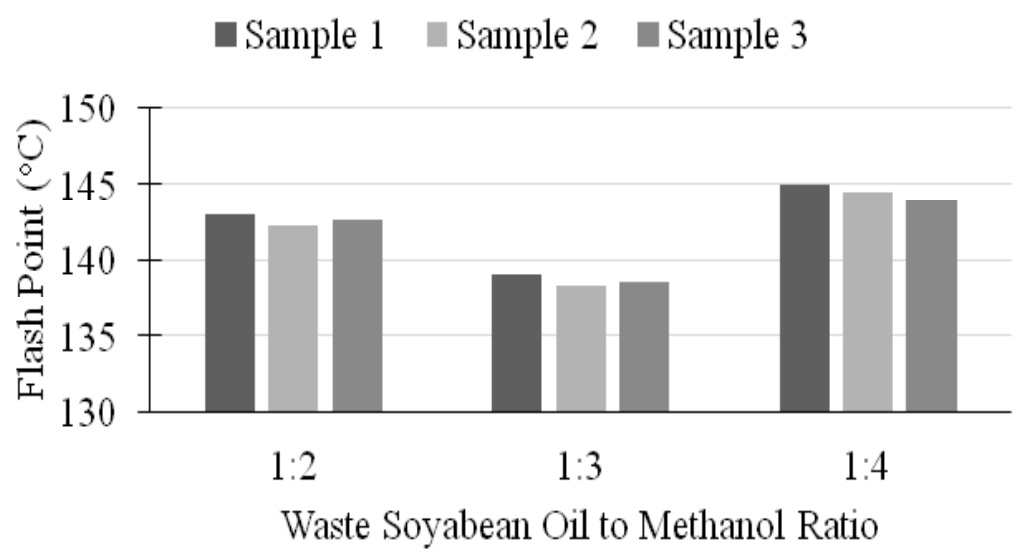

Fig. 13: Flash Point of Different Samples of Biodiesel

\section{Relative Density}

The relative density for different samples of waste soya bean and cottonseed biodiesel at room temperature was found and presented in Fig. 9. The relative density of different samples of waste soya bean at room temperature were found in the range of 880 to $905 \mathrm{~kg} / \mathrm{m}^{3}$ which was in the range 800 to $900 \mathrm{~kg} / \mathrm{m}^{3}$ at $15^{\circ} \mathrm{C}$ temperature recommended by ASTM D 6751. The biodiesel extracted at 1:3 molar ratio had lowest relative density of $878 \mathrm{~kg} / \mathrm{m}^{3}$

The American standard for biodiesel, ASTM D 6751, sets a maximum limit of $0.80 \mathrm{mg} \mathrm{KOH} / \mathrm{g}$ oil for acid value. The acid value for different samples of waste soya bean biodiesel was evaluated and presented in Fig. 10. The acid value of different samples were in range of 0.42 to $0.70 \mathrm{mg} \mathrm{KOH} / \mathrm{g}$ oil. The lowest acid value of $0.42 \mathrm{mg}$ of $\mathrm{KOH} / \mathrm{g}$ oil was obtained in biodiesel produced at 1:3 molar ratio and which below than maximum limit of $0.80 \mathrm{mg} \mathrm{KOH} / \mathrm{g}$ oil recommended by ASTM D 6751.

\section{Gross heat of combustion}

Gross heat of combustion for different samples of waste soya bean biodiesel was found by drawing three random samples from extracted biodiesel and shown in Fig. 11. The calorific value of different samples were found in range of 40.8 to $41.3 \mathrm{MJ} / \mathrm{kg}$. The highest calorific value of $41.3 \mathrm{MJ} /$ $\mathrm{kg}$ was recorded with sample 3 of 1:4 proportion.

\section{Kinematic viscosity}

The kinematic viscosity for different samples of waste soya bean biodiesel was found and shown in Fig. 12 with the help of standard red wood viscometer. The kinematic viscosity of waste soya bean biodiesel was found in the range of 4.72 to $5.13 \mathrm{cSt}$ which was in the range of 1.6 to $6 \mathrm{cSt}$ as recommended by ASTM D 445. The biodiesel produced at 1:3 molar ratio had lower kinematic viscosity than other samples

\section{Flash point}

The American standard for biodiesel (ASTM D 93) sets a minimum limit for the flash point of $130^{\circ} \mathrm{C}$. The flash point for different samples of waste soya bean biodiesel was found with the help of Pensky Martin's flash point apparatus and shown in Fig. 13. The flash point values for different proportions of waste soya bean biodiesel was found in the range of 139 to $146^{\circ} \mathrm{C}$ which was above the minimum limit recommended by ASTM D 93. It was also observed that, the flash point of waste soya bean biodiesel prepared at 1:3 proportion had lower than other biodiesel samples.

\section{CONCLUSIONS}

The study of laboratory scale production and characterization of waste soya bean biodiesel had following conclusions as

1. The maximum biodiesel yield of $76 \%$ was obtained at $1: 3$ oil to methanol molar ratio \& $1.0 \%$ of $\mathrm{KOH}$ concentration.

2. The relative density of different samples of waste soya bean at room temperature were found in the range of 880 to $905 \mathrm{~kg} / \mathrm{m}^{3}$ which was in the range 800 to $900 \mathrm{~kg} / \mathrm{m}^{3}$ at $15^{\circ} \mathrm{C}$ 
temperature recommended by ASTM D 6751. The biodiesel extracted at 1:3 molar ratio had lowest relative density of $878 \mathrm{~kg} / \mathrm{m}^{3}$.

3. The acid value of different samples were in range of 0.42 to $0.70 \mathrm{mg} \mathrm{KOH} / \mathrm{g}$ oil. The lowest acid value of $0.42 \mathrm{mg}$ of $\mathrm{KOH} / \mathrm{g}$ oil was obtained in biodiesel produced at 1:3 molar ratio and which below than maximum limit of $0.80 \mathrm{mg} \mathrm{KOH} / \mathrm{g}$ oil recommended by ASTM D 6751 .

4. The calorific for different samples were found in the range of 40.8 to $41.3 \mathrm{MJ} / \mathrm{kg}$. The highest calorific value of $41.3 \mathrm{MJ} / \mathrm{kg}$ was recorded with sample 3 of 1:4 proportion.

5. The kinematic viscosity of waste soya bean biodiesel was found in the range of 4.72 to $5.13 \mathrm{cSt}$ which was in the range of 1.6 to 6 cSt as recommended by ASTM D 445. The biodiesel produced at 1:3 molar ratio had lower kinematic viscosity than other samples.

6. The flash point of waste soya bean biodiesel prepared at 1:3 proportion had lower than other biodiesel samples.

\section{REFERENCES}

1. Debrimas, A. Biodiesel fuels from vegetable oils via catalytic and non-catalytic super critical alcohol transformation and other methods: a survey. Energy Conversion and Management, 44: 2093-2109 (2003).

2. Canakci, M. The potential of restaurant waste lipids as biodiesel feedstock's. Bio resource Technology, 98 (1): 183-190 (2007).

3. Mittelbatch, M., Pokits, B. and Siberholz, A. Diesel fuel derived from vegetable oils, IV: production and fuel properties of fatty acid methyl ester from used frying oil. In: Liquid fuels from Renewable Resources, Proceeding Alternative Energy Conference, American Society of Agricultural Engineers, st. Joseph, MI, 74 (1992).

4. Demirbas A. Progress and recent trends in biodiesel fuels. Energy Conversion and
Management, 50:14-34 (2009).

5. Encinar, J. M., González, J. F., RodríguezReinares, A. Biodiesel from used frying oil. Variables affecting the yields and characteristics of the biodiesel. Ind. Eng. Chem. Res., 44:5491-5499 (2005).

6. Abdullah, N. H., Hasan, S. H., Yusoff, N.R.M, Biodiesel Production Based on Waste Cooking Oil (WCO). International Journal of Materials Science and Engineering, 1(2):9499 (2013).

7. Hossain, A. B. M. S., Nasrulhaq, B.A., Salleh, A. and Chandran, S., Biodiesel production from waste soybean oil biomass as renewable energy and environmental recycled process. African Journal of Biotechnology, 9(27): 42334240 (2010). 